\title{
Personal Exposure to Air Pollution for Various Modes of Transport in Auckland, New Zealand
}

\author{
K.N. Dirks ${ }^{*}$, P. Sharma, J.A. Salmond and S.B. Costello
}

The University of Auckland, Auckland, New Zealand

\begin{abstract}
This paper investigates the carbon monoxide (CO) doses received while commuting by different modes (car, bus, train, motorcycle, bicycle and running), taking into account the commute time as well as the level of physical activity required. While the participants were constrained to travel at specific peak traffic times and between designated start and end points, they were free to choose a route appropriate for their mode of transport.

The results of this study suggest that the lowest exposures (concentrations of pollutants) are experienced by train commuters, largely a reflection of the routes being removed from any significant road traffic. Motorcyclists experienced significantly higher average concentrations as a result of high-concentration and very-short-duration peaks not seen in the traces of car and bus commuters travelling on the same road. Travel by bus along a dedicated busway was also found to be effective in reducing commuter air pollution exposure compared to travel by car on a congested stretch of motorway.

The average concentrations to which cyclists and runners were exposed were found to be not significantly different for those travelling by car or bus (except when on dedicated pedestrian/cycleways). However, when the increased physical activity that is required is taken into account (leading to higher volumes of air breathed) along with the increased commuting time (especially in the case of runners), the air pollution doses (as estimated by the product of the concentration, commute time and breathing factor) were found to be significantly higher than for the motorised modes. The results suggest that separate pedestrian/cycleways go some way towards providing healthier options for cyclists and pedestrians.
\end{abstract}

Keywords: Urban air quality, exposure, uptake, carbon monoxide, commuting, vehicle emissions.

\section{INTRODUCTION}

Recent studies suggest that people are exposed to some of their highest concentrations of atmospheric pollutants while commuting [1]. The amount of time spent either on or in close proximity to busy roads is therefore expected to be important in assessing individual exposure to road traffic pollution. In addition, the choice of mode, which determines proximity to the road (on the footpath for example) and route taken (shortcuts through recreational parks away from roads) also become important. Moreover, in active modes, such as cycling and running/walking, the increased level of physical activity and often increased commute time mean that an increased volume of polluted air is inhaled compared to the same exposure for a commuter travelling by car or bus. However, to date, few commuting studies investigating exposure to air pollution have considered the pollutant dose (a function of the concentration, commute time and breathing rate) as well as exposure (as measured by mean ambient concentration). Perhaps as a consequence, although the acute effects of exposure to high doses of air pollutants in the laboratory are well known, the effects of exposure to lower, more realistic, doses of urban ambient pollutants remain poorly understood $[2,3]$. Certainly lack of high quality exposure data has hampered the investigation between exposure to ambient air pollutants and human health impacts [4].

*Address correspondence to this author at The University of Auckland, Auckland, New Zealand; Tel: 64-9-373-7599, Ext: 89755; Fax: 64-9-3737503; E-mail: k.dirks@auckland.ac.nz
Many studies have been carried out in different parts of the world to try to gain a better understanding of personal exposure to air pollutants while commuting by different modes [5-8], aided by the recent development of portable air quality monitoring technology. Although the results from such studies are frequently complex and sometimes contradictory due to a large number of confounding factors [9], typically they show that the mean concentrations of air pollutants pedestrians and cyclists are exposed to are lower than those experienced by car drivers and bus passengers $[10,11]$. It is believed that this is due to the additional options available for pedestrians and cyclists to travel at least part of their journey through parklands and backstreets. Also, pedestrians use the curbside which is removed somewhat from the main line of traffic [12].

For motorised passengers, several studies suggest that the concentrations bus commuters are exposed to are less than those experienced whilst travelling by car $[1,13]$. Explanations for this include the low-lying position of car commuters relative to bus commuters [14], the ventilation mode $[14,15]$ as well as the fact that buses travel near the curbside of the road rather than in the middle lanes $[1,13,16]$. Exposure in buses has been shown to be highly correlated to ambient concentrations, but also affected by the bus' own exhaust emissions [17]. Most studies have found that motorcyclists are exposed to higher concentrations relative to car and bus commuters [18-20]. This may be due to the fact that motorcyclists travel in close proximity to tailpipe exhaust emissions [16], with little or no physical barrier 
between the exhaust and the motorcyclist's respiratory system. Nearly all studies consider exposures along a predetermined route $[1,13,21]$, even though, in reality, there often exist different route options for different modes.

Only a few studies consider the increased ventilation rate associated with active modes. One study [22] showed that the minute ventilation rate (product of the breathing rate and the volume of air per breath) of cyclists was on average twice that of car commuters (an increase from $12 \mathrm{~L} \mathrm{~min}^{-1}$ to $24 \mathrm{~L} \mathrm{~min}^{-1}$ ) and two studies $[21,23]$ suggest $31 \mathrm{~L} \mathrm{~min}^{-1}$, and 40-60 L min ${ }^{-1}$ for cyclists, respectively. No studies could be found specifically in relation to the exposure of commuters who run to work, though one would expect these to be comparable or higher than those of cyclists, noting that they are also highly variable depending on an individual's level of fitness and individual choice of intensity of physical exercise.

In addition to the activity level, an individual's dose is also influenced by the travel time. Some studies specifically mention the commuting period as a factor in assessing the air pollution dose associated with commutes [20]. To date, one of the only studies to consider both the commuting duration and the activity level of the commuter in assessing air pollution exposure and health risk is that of Panis et al. [21]. A limitation of this study is that only car and bicycle modes are considered.

The first aim of the present study is to build on the work of Panis et al. [21] by investigating other common modes such as travel by motorcycle, by bus, train and running, in addition to car and bicycle travel. As with this study [21], consideration is made of the commute time and physical activity level of the commuter, with the latter based on values suggested in the literature, in addition to the average concentration to which the commuter is exposed during their journey. This is done in order to provide more realistic estimates of the relative air pollution dose received while commuting. Another feature of the present study is that each commuter is free to choose the route that most suits their mode between fixed end points. This is in contrast with most of the existing studies in which participants travel along a predetermined route. This further enables an investigation into the effectiveness of dedicated bus lanes and pedestrian/cycleways in terms of air pollution exposure.

The study consist of a three-week field campaign carried out in Auckland, New Zealand in which concentrations of carbon monoxide were measured by commuters travelling the same journey (start and end points) but by different modes and by their preferred route at specified times of the day associated with peak commuting periods. Carbon monoxide was chosen as the pollutant of interest as traffic emissions are its major source and reliable portable technology exists for its measurement. Average concentrations and commute times are compared between modes and the impact of activity level and travel time on dose are considered in relation to active transport modes.

\section{METHODOLOGY}

\section{Study Site}

Auckland is the largest city in New Zealand with a population of $1,436,500$, equivalent to about a third of the country's population [24]. Fieldwork was carried out over the spring period from 8 November to 17 December 2010. Three routes into the city were selected to represent the variety of different commutes that Aucklanders experience from day to day: one from the north (Albany), one from the east (Glen Innes) and one from the west (Waterview). Fig. (1) shows Auckland's coastline, major roads and the routes chosen by the commuters for the study, constrained by the start and end points. Sampling was carried out for one week along each of the routes.

\section{Route 1}

Travel to and from the west (Waterview) can be achieved by bus (which follows a busy arterial road), or by car/motorcycle along a stretch of motorway. In addition, a separate pedestrian/cycleway exists along a significant portion of the motorway route, allowing a convenient alternative for cyclists and runners/walkers. The transverse distance between the edge of the motorway and the pedestrian/cycleway varies between about $4 \mathrm{~m}$ and $20 \mathrm{~m}$. The annual average daily traffic on the motorway at this point can exceed 120,000 on some sections [25]. The journey is $7.5 \mathrm{~km}$ in distance. Because of bus route constraints, the bus commuter had a different end point than the other commuters but the journey distance was the same (see Fig. 1).

\section{Route 2}

Commuting from the north of the city requires travel across a bridge limiting transport options to car and bus. There is no train service and no access for pedestrians or cyclists. The recently-constructed Northern Busway is a physically-separated two-way road running parallel to the motorway built exclusively for buses. The annual average daily traffic on the harbour crossing can reach almost 160,000 [25]. The journey is $20.7 \mathrm{~km}$ in distance.

\section{Route 3}

Travel from the eastern suburbs presents a variety of different options including travel by bus, car, bicycle and walking/running. Many different route choices exist including segments of motorway, busy arterials and quieter streets. There is also a commuter train that runs directly into the city centre. The journey is approximately $12 \mathrm{~km}$ in distance, depending on the specific route taken.

Each of the participants recruited for the study was a regular commuter on their chosen mode. Each was asked to time their journeys in such a way as to arrive at work for a 9:00AM start (or as close as practically possible given the uncertainty associated with day-to-day variability in traffic patterns) and leave for home at 5:00PM. Six modes of commuting were selected: car, bus, train, motorcycling, bicycling and running. Two of the routes had restrictions in terms of possible modes, as discussed above. Each commuter was free to choose whatever route was most appropriate for the chosen mode. For example, the cyclist and runner were free to use bicycle lanes and take shortcuts through parks and quiet streets where suitable. The bus commuter was obviously restricted to whatever route the bus took but could choose whatever bus number was the most appropriate for the required journey. All participants were non-smokers. In 


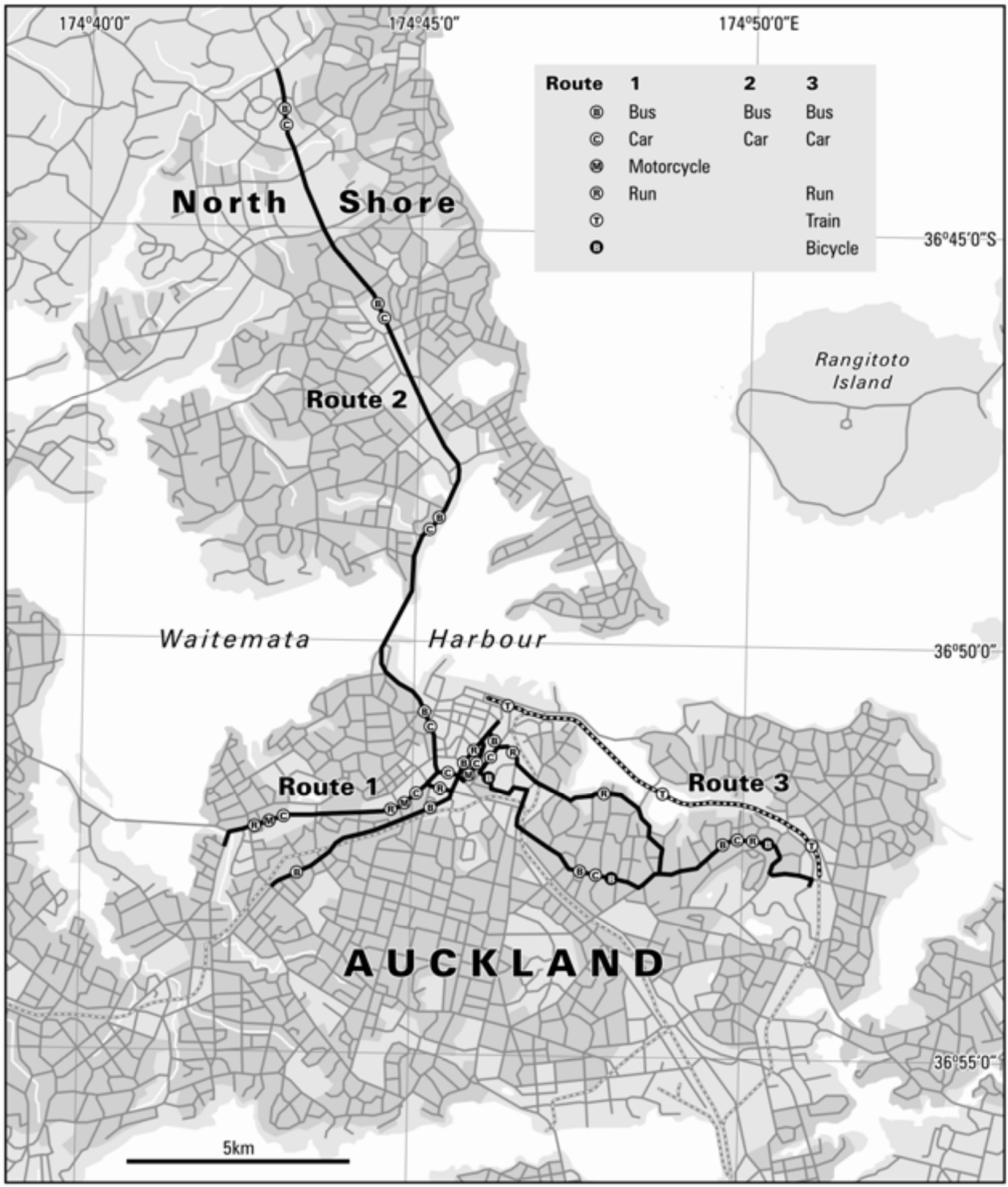

Fig. (1). Map of the Auckland Region and the routes chosen for the study. Note that while the start and end points were specified, the commuters were free to choose the specific route.

total, data from 88 commutes were collected, ranging from four to ten per mode per route.

\section{Air Quality Monitoring Equipment}

Each of the participants carried a Langan T15n portable carbon monoxide monitor (from Langan Products Inc.) used in many of the studies of personal exposure found in the literature $[13,19]$. The monitor has a resolution of $0.05 \mathrm{ppm}$ and a range of $0-200 \mathrm{ppm}$. In each case, the monitor was placed as close as practical to the commuter's face. The participants were asked to log the start and end times of their journeys, and, once chosen, to stick to their preferred route for the duration of the study. 


\section{Exercise Factors and Dose}

For those travelling by car, bus or train, a resting minute ventilation rate of $12 \mathrm{~L} \mathrm{~min}^{-1}$ was assumed, as suggested by two previous studies $[21,22]$. The cyclist was assumed to have a minute ventilation rate of $36 \mathrm{~L} \mathrm{~min}^{-1}$ (within the range of 24-60 L min') and the runner a moderate level of $48 \mathrm{~L}$ $\min ^{-1}$, both within the range of values reported in the literature [21-23].

The commuter 'dose' was defined as:

Dose $\left(\mathrm{ppm}^{*} \mathrm{~h}\right)=[\mathrm{CO}](\mathrm{ppm}) *$ Commute time $(\mathrm{h}) *$ Exercise factor

where the exercise factor was defined as the ratio of the minute ventilation factor for a particular mode to the resting rate experienced by those commuting via sedentary modes e.g. $36 \mathrm{~L} \mathrm{~min}^{-1}$ over $12 \mathrm{~L} \mathrm{~min}^{-1}$. In this case, the exercise factor for the cyclist and runner were assumed to be 3.0 and 4.0 , respectively, based on the range of values suggested by the studies mentioned above [21-23]. The dose was then calculated based on the recorded commute time, the observed carbon monoxide concentrations recorded with the Langan portable monitor, and the estimated exercise factor. All analyses were carried out using the SPSS Statistical Package V18.

\section{RESULTS}

Table 1 presents the descriptive statistics of the observations. The median 1-minute concentrations ranged from $0.0 \mathrm{ppm}$ for the runner on Route 3 to $3.8 \mathrm{ppm}$ for the motorcyclist on Route 1 for each of the modes and routes. The highest 1-minute concentration was $176 \mathrm{ppm}$ observed during a motorcycle commute. The mean commute times ranged from 19 minutes for the motorcyclist on Route 1 to 67 minutes for the runner on Route 3.

Fig. (2) is an example of an evening commute for Route 3 . Note the very high variability in the concentrations experienced by the cyclist compared to the car commuter,

Table 1. Descriptive Statistics of Commuting Data Including Exposure (Average Carbon Monoxide Concentration) and Dose for Each of the Modes and Each of the Routes Based on the Mobile Carbon Monoxide Concentrations, Measured Commute Times and Exercise Rates (Assumed as Fixed Values According to Mode)

\begin{tabular}{|c|c|c|c|c|c|c|c|}
\hline Route & Mode & $\begin{array}{l}\text { Number of } \\
\text { Commutes }\end{array}$ & $\begin{array}{l}\text { Mean } \\
{[\mathrm{CO}]} \\
\text { (ppm) }\end{array}$ & $\begin{array}{c}\text { Maximum } \\
\text { 1-min }[\mathrm{CO}] \\
\quad(\mathrm{ppm})\end{array}$ & $\begin{array}{c}\text { Commute } \\
\text { Time (h) } \\
\text { Mean } \pm \text { SD }\end{array}$ & $\begin{array}{l}\text { Breathing } \\
\text { Factor } \\
\text { (Assumed) }\end{array}$ & $\begin{array}{c}\text { Dose } \\
\left(\text { ppm }^{* h}\right) \\
\text { Mean } \pm \text { SD }\end{array}$ \\
\hline \multirow{2}{*}{$\begin{array}{c}\text { Route } 1 \\
\text { (Avondale) }\end{array}$} & Car & 10 & 1.0 & 2.4 & $0.43 \pm 0.12$ & 1.0 & $0.4 \pm 0.3$ \\
\hline & Run & 10 & 0.4 & 5.8 & $0.82 \pm 0.04$ & 4.0 & $1.2 \pm 0.7$ \\
\hline \multirow{2}{*}{$\begin{array}{l}\text { Route } 2 \\
\text { (Albany) }\end{array}$} & Bus & 10 & 0.7 & 4.2 & $0.80 \pm 0.08$ & 1.0 & $0.5 \pm 0.2$ \\
\hline & Car & 5 & 2.0 & 6.5 & $0.58 \pm 0.16$ & 1.0 & $1.2 \pm 0.4$ \\
\hline \multirow{2}{*}{$\begin{array}{c}\text { Route } 3 \\
\text { (Glen Innes) }\end{array}$} & Bus & 5 & 0.5 & 1.9 & $0.80 \pm 0.10$ & 1.0 & $0.3 \pm 0.3$ \\
\hline & Car & 9 & 0.7 & 3.5 & $0.33 \pm 0.08$ & 1.0 & $0.3 \pm 0.2$ \\
\hline
\end{tabular}

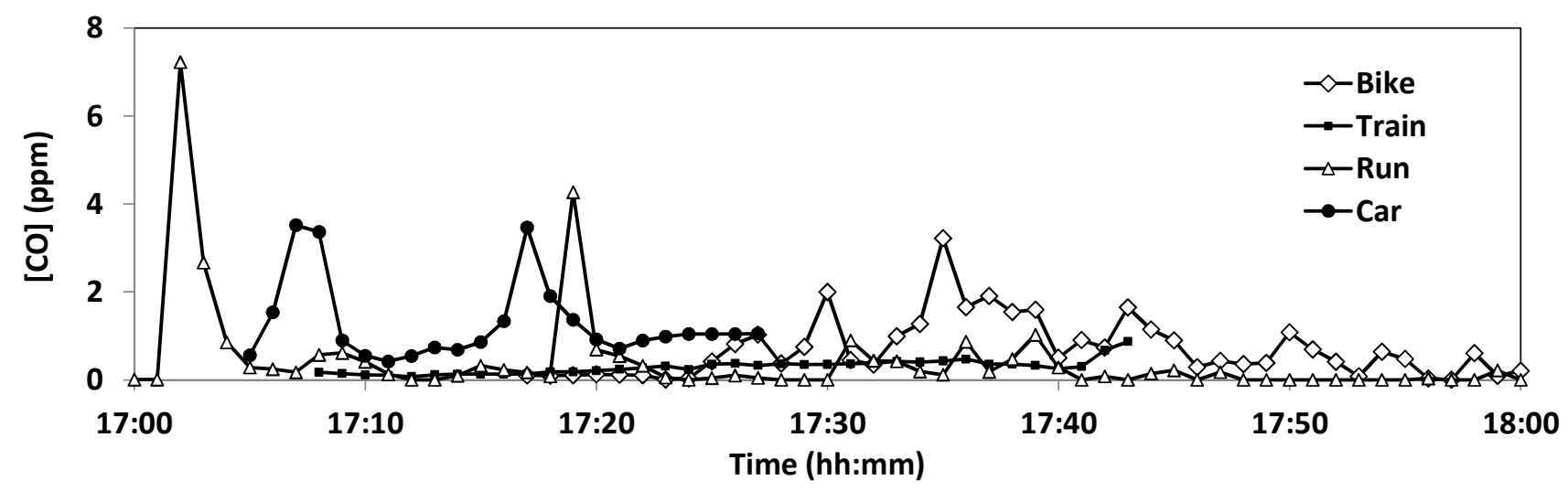

Fig. (2). Example of a time series of carbon monoxide concentrations associated with a single commute comparing four different modes. 
the long commute time for the runner, and the consistently low concentrations experienced by the train commuter. The runner experienced high peaks in concentrations associated with travel on a busy road and then while crossing a busy intersection, both at the city end of the commute. Following this, they experienced low concentrations while travelling along a relatively quiet road.

Fig. (3) presents box plots of 1-minute average concentrations (data from all commutes combined) for each route and each mode. A log transformation was applied as the data were highly skewed. A remarkable result is the significant number of very high concentrations measured by the motorcyclist. Such concentrations were not measured by any other mode or route and occurred on more than one of the motorcycle commutes.

A comparison of the commute average exposures (carbon monoxide concentrations) as well as the doses (as defined in Equation 1) between modes for each of the routes revealed statistically significant differences $(p<0.05)$ for all of the routes, as shown in Table 2 and Fig. (4). Given these results, post-ANOVA procedures were also carried out. Table $\mathbf{3}$ presents the results of contrasts following ANOVA to determine wherein the differences lie with respect to the different commuting modes, both in terms of exposures as well as doses (statistically significance assumed for $\mathrm{p}<0.05$ in both cases). The results of the commuter exposure and commuter dose post-ANOVA analysis are presented each in turn below.

\section{Commuter Exposure}

The post-ANOVA analysis suggests that motorcyclists experience much higher exposures than other commuters travelling on the road (Test 1 of Table 3 ). The runner was found to have a significantly lower mean exposure than for the bus and car commuter for the route along which there was a dedicated pedestrian/cycleway (Test 2 of Table 3 ) but not significantly different for the route where the runner simply chose a less congested route (Test 9 of Table 3 ). This suggests that pedestrian/cycleways are effective in reducing exposures for runners. Also, the less congested route for the runner was only an option once the runner had left the city centre and high peaks in exposure were observed at the beginning of the commute home, as seen in Fig. (2). No statistically significant difference was found between the bus and car exposure for Route 1 (Test 3 of Table 3 ).

On Route 2, where there was a separate two-way busway alongside the motorway, the mean exposures for the car driver were significantly lower than for the car commuter $(\mathrm{t}$ $=8.55, \mathrm{p}=<0.001)$. This suggests that removing buses from traffic flow along motorways is effective.

For Route 3 when travel by train was an option, it was found that the mean exposure of the train commuter was significantly lower than for any other mode (Test 10 of Table 3). Much of the train route was well away from any road. When contrasting the exposure for the car and bus commuters with the active mode commuters (runner and cyclist) it was found that the exposures were not significantly different. As stated above, despite the runner choosing a less congested route, their exposure was not found to be lower when compared to those of the bus, car and bicycle commuters (Test 12). (a)

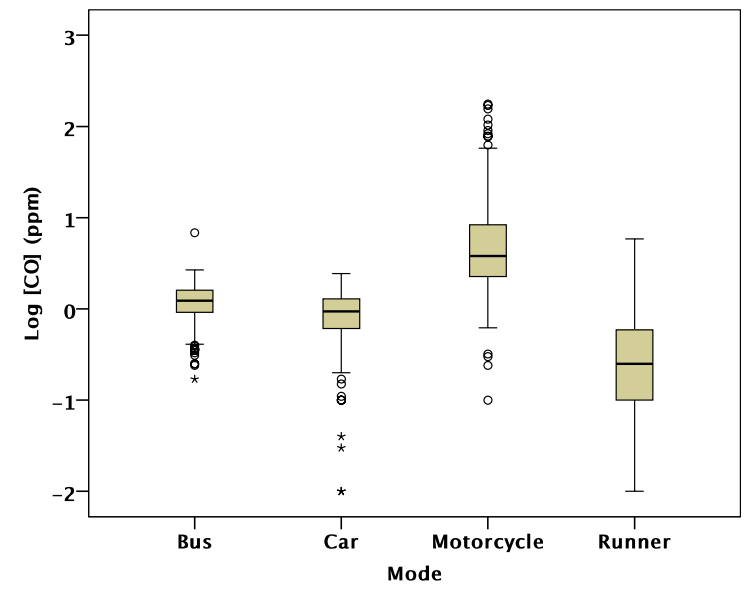

(b)

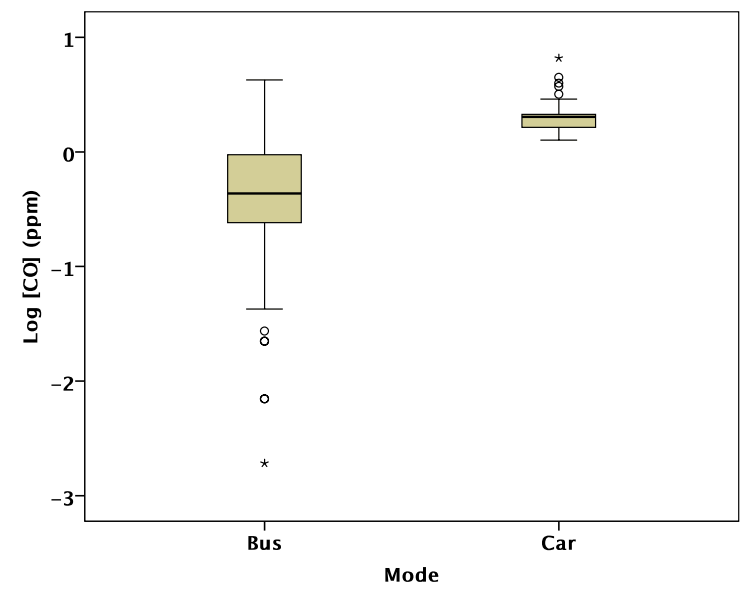

(c)

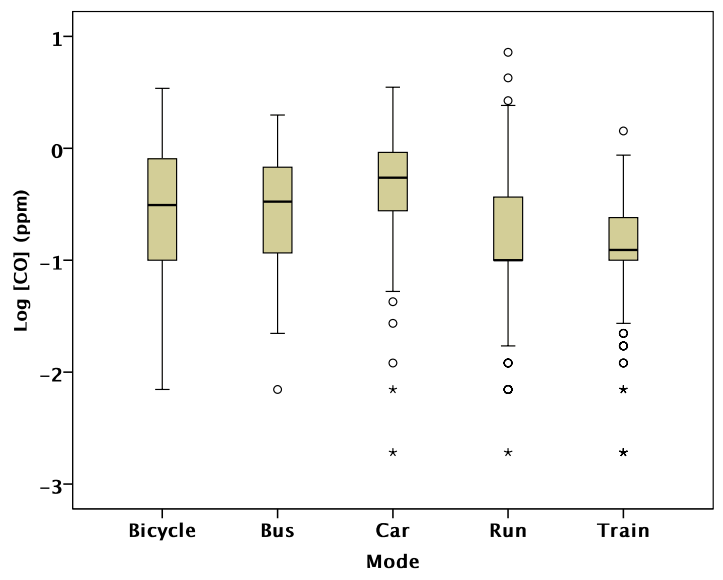

Fig. (3). Box plots of 1-minute averaged carbon monoxide concentrations for each of the modes and each of the routes a) Route 1 b) Route 2 , c) Route 3 . Note that 0 ppm values have been set to $0.1 \mathrm{ppm}$ to allow plotting as a log. 
Table 2. ANOVA Statistics Comparing the Means Exposures and Doses for Each of the Modes within Each of the Routes (Statistical Significance was Assumed at $\mathbf{p}<\mathbf{0 . 0 5}$ )

\begin{tabular}{|cccccc|}
\hline $\begin{array}{c}\text { Exposure } \\
\text { or Dose }\end{array}$ & Route & F & $\begin{array}{c}\text { Degrees of Freedom } \\
\text { k-1 }\end{array}$ & n-k & p \\
\hline \hline $\begin{array}{c}\text { Exposure } \\
(\mathrm{ppm})\end{array}$ & 1 & 14.87 & 3 & 34 & $<0.001$ \\
& 2 & 13.14 & 1 & 12 & 0.003 \\
\hline Dose & 3 & 4.35 & 4 & 28 & 0.007 \\
$(\mathrm{ppm} * \mathrm{~h})$ & 2 & 7.32 & 3 & 34 & 0.001 \\
& 3 & 9.52 & 4 & 12 & $<0.001$ \\
& & & & 28 & $<0.001$ \\
\hline
\end{tabular}

Table 3. Post-ANOVA Statistics to Determine wherein the Differences Lie with Respect to the Various Modes of Commuting, Both for Exposure As Well As for Dose. The Order of the Modes for the Contrast Coefficients is Route 1: (Bus, Car, Runner, Motorcycle) Route 3: (Bus, Car, Run, Bike, Train). The Test Numbers (Column 1) are for Reference in the Text. Statistical Significance was Assumed at $\mathbf{p}<\mathbf{0 . 0 5}$

\begin{tabular}{|c|c|c|c|c|}
\hline Test & Exposure or Dose & Route & Contrasts & $\mathbf{p}$ \\
\hline 1 & Exposure & 1 & $110-2$ & 0.012 \\
\hline 2 & $(\mathrm{ppm})$ & 1 & $11-20$ & $<0.001$ \\
\hline 3 & & 1 & $1-100$ & 0.078 \\
\hline 4 & Dose & 1 & $110-2$ & 0.038 \\
\hline 5 & $\left(\mathrm{ppm}^{*} \mathrm{~h}\right)$ & 1 & $11-20$ & 0.015 \\
\hline 6 & & 1 & $1-100$ & 0.044 \\
\hline 7 & Exposure & 3 & $1111-4$ & $<0.001$ \\
\hline 8 & (ppm) & 3 & $11-1-10$ & 0.574 \\
\hline 9 & & 3 & $11-310$ & 0.179 \\
\hline 10 & Dose & 3 & $1111-4$ & 0.004 \\
\hline 11 & $\left(\mathrm{ppm}^{* h}\right)$ & 3 & $11-1-10$ & 0.013 \\
\hline 12 & & 3 & $11-310$ & 0.182 \\
\hline
\end{tabular}

\section{Commuter Dose}

When considering the dose (taking into account the commute time and breathing factor) some different results are obtained (see Fig. 4). For Route 1, while the runner experienced a significantly lower exposure compared to the bus and car commuters, their dose was significantly higher (Test 5 of Table 3). This is a reflection of the higher ventilation rate of the runner as well as the increased commute time. For Route 3, while the active mode exposures associated with running and cycling were found to be not significantly different from the car and bus commuter exposures (Test 8 of Table 3 ), they were significantly higher when considering the dose (Test 11 of Table 3 ).

\section{DISCUSSION}

Over the last ten years or so, interest in outdoor ambient air pollution monitoring has tended to move away from carbon monoxide and towards other pollutants such as NOx and particulate matter. This is due to the limited direct health impacts associated with exposure to modest amounts of carbon monoxide. There has also been a gerneral decrease in the ambient concentrations of carbon monoxide measured in recent years as a result of improved vehicle technology. However, carbon monoxide measurements are strongly related to road traffic emissions, and generally highly correlated with NOx. As such, it can been seen as a good marker for road traffic emissions.

There have also been significant advances in compact portable air sampling technology which facilitate studies investigating personal exposure. And indeed, many of the exposure studies mentioned above have considered carbon monoxide in their analyses. In the present study, the running commuter required a device that was sufficiently light to allow for a comfortable commute. While such technology is available for the measurement of carbon monoxide, cheap, reliable devices which are not sensitive to motion are not readily available for the measurement of other pollutants. For these reasons, for the present study, carbon monoxide was chosen as the pollutant of interest.

Of all of the modes of commuting, the highest mean exposures were experienced by the motorcyclist. This is consistent with the results of other studies found in the literature [18-20].

Those travelling by train were found to experience the lowest air pollution concentrations, as the train travelled on its own dedicated track, well removed from any road traffic. Apart from the train's own engine, a possible additional source of carbon monoxide on board trains may have been from the exhaled air of smokers having smoked a cigarette immediately prior to boarding the train. The same applies for buses.

Apart from the motorcycle, in general, the average $\mathrm{CO}$ exposures were found to be highest for car and bus users. The international literature explains that this is due to the fact that cars travel in the main line of traffic where pollution levels are expected to be at their highest [14]. In congested traffic conditions, there is also much scope for tailpipe emissions from the car in front to be drawn into the air ventilation system, polluting the vehicle's passenger compartment. In very congested conditions, commuting by car can also be the most time-consuming mode of transport, maximising exposure time and therefore dose.

On the route where there was a separate two-way busway, the exposures experienced by those travelling on the bus were significantly lower than those on the congested motorway. This is supported by an exposure study carried out in Pakistan which showed a strong association between traffic congestion and increased commuter exposure [26]. Separate bus routes allow buses to travel more freely than passenger cars, potentially reducing commute times. Interestingly however, when the bus travelled in more congested traffic along main arterial roads the passengers 
a)
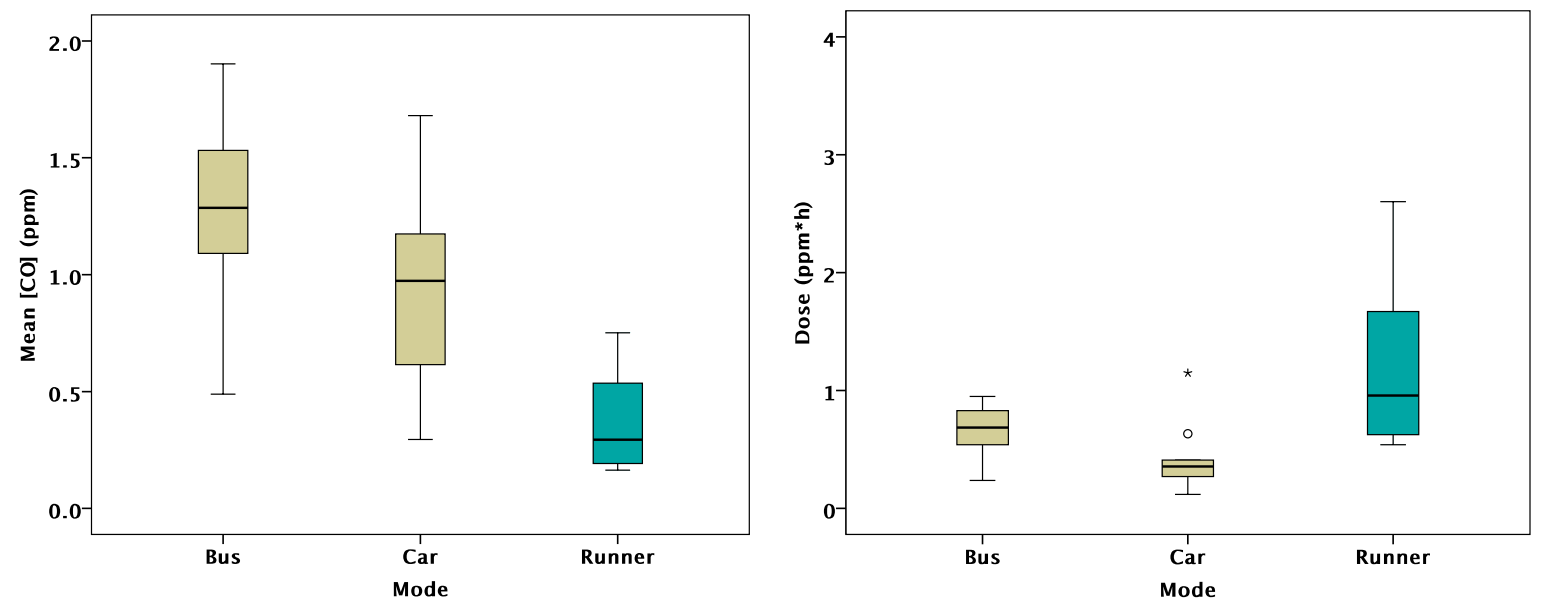

b)
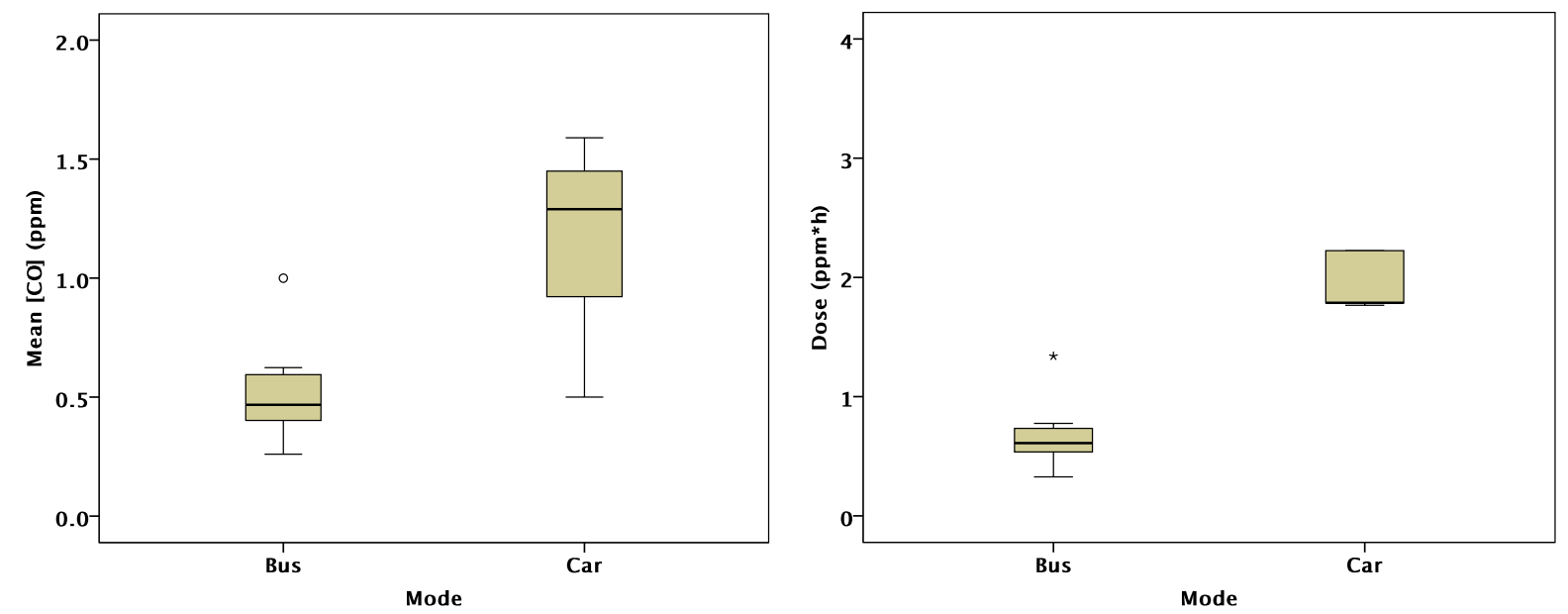

c)
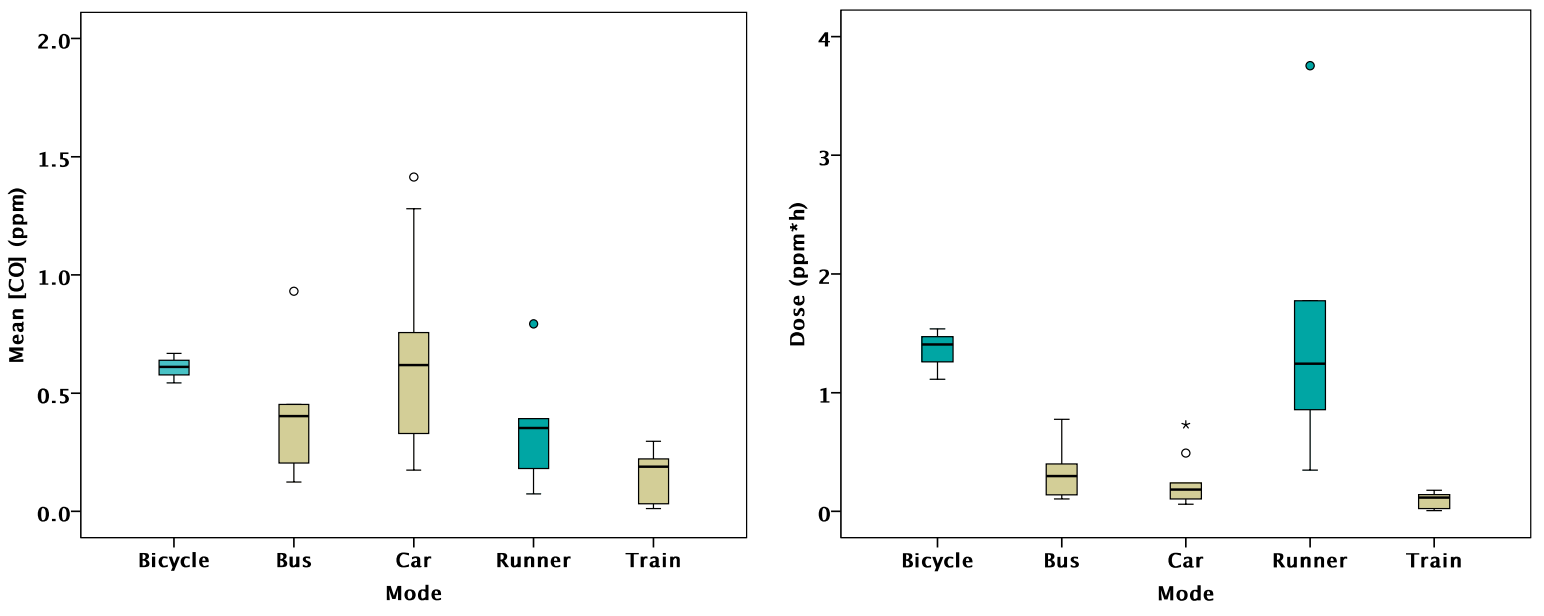

Fig. (4). Comparison between commute average concentrations and uptake for each of the modes and each of the routes a) Route 1 b) Route 2 c) Route 3 . The darker boxes indicate the active transport modes. 
were not significantly different from those travelling in the car in the more free flowing traffic on the motorway (Route 1). Furthermore, the particular bus in which the commuter travelled during this week was not air conditioned so ventilation was provided by open windows, allowing air to flow freely in and out of the bus. This is an interesting result as it demonstrates that due to the high temporal and spatial variability in $\mathrm{CO}$ concentrations, other variables (such as ventilation rate and proximity to emissions) may be more important in determining exposure than choice of transport mode.

For the runner, exposures were lower than for the car and bus commuters when running along the dedicated footpath/cycleway but not significantly lower when travelling along a less congested road, mainly because of an inability to avoid congested intersections at the city end of the commute. This result is supported by a Utrecht study who found that considerably lower exposures could be achieved simply by choosing a less congested route [3]. The cyclist experienced high exposures for the route that required travel along a busy arterial. Irrespective of the route, and whether or not there was a dedicated pedestrian/cycleway, the doses received by active mode commuters were significantly high that for bus or car commuters.

In all of analysis, it has been assumed that the active mode commuters have a breathing factor of 3 or 4 (for cyclists and runners, respectively). In reality, this will vary significantly depending on the amount of physical exertion put in by the commuter and also their level of fitness. Another significant factor is the topography. The topography of Auckland is undulating. In areas of high traffic density in particular, the actual dose experienced by the commuter will vary considerably depending on whether the commuter is travelling uphill or downhill. While this is an important consideration, it is beyond the scope of the present study and the subject of a follow-up study. This study further emphasises the need highlighted by Kingham and Dorset (2011) [4] for high quality exposure studies which take into consideration the variations in exposure resulting from personal choices in commuter mode, route and duration of travel as well as intraurban variation in ambient air quality generated by local microenvironments.

\section{CONCLUSIONS}

The results of this study suggest that commuting by active modes such as by bicycle and running can result in higher doses of pollution than commuting by bus or by car, even when routes are chosen that have dedicated pedestrian/cycleways along part of their journey. While these are effective for the portions of the commute where they exist, in the city where pedestrians and cyclists merge with the motorised traffic, the highest exposures are observed, which, when combined with high rates of activity lead to large doses of pollution. The effectiveness of such separate pedestrian/cycleways would therefore be improved considerably if they were extended to the city centre. Clearly, providing incentives for people to take the bus rather than rely on cars will also help reduce the traffic flows and congestion.

As in many cities worldwide, Auckland transport policy has historically tended to lean towards building new roads, instead of controlling the amount of traffic on the existing roads. Congestion charging schemes such as those introduced in Singapore and London, which have lead to a decrease of $40 \%$ and $30 \%$, respectively, in traffic in the central business districts of both cities [27], have the potential to transform urban cities into more sustainable and liveable environments. In urban cities where people prefer using private modes of transport (cars) for commuting, as is the case in Auckland, work is needed to change people's perception of public transport and thereby lead to changes in behaviour. This can be achieved by informing both the public and policymakers about the environment and health implications of their transport choices. More importantly, an effective public transportation system is needed to give people cost-effective and efficient transport choices.

In addition, the strategic expansion of the cycle lane and footpath network through parklands and roads joining suburban areas would also encourage walking and cycling away from mains roads and busy intersections. This would help to ensure healthier journeys for those that choose active modes of transport.

\section{ACKNOWLEDGEMENTS}

Mr. Brendan Hall (School of Environment, The University of Auckland) and Mr. Vincent Dirks are thanked for their help with the project logistics. Mr. Lee Langan of Langan Products, Inc. is thanked for the excellent technical support provided for the portable air quality monitors. The anonymous reviewers are thanked for their useful comments on the original manuscript. This work was funded by a Cross Faculty Research Initiatives Grant from The University of Auckland (Research Grant 3626726). Ethical approval was obtained from The University of Auckland Human Participants Ethics Committee (2010/405).

\section{CONFLICT OF INTEREST}

None declared.

\section{REFRENCES}

[1] Duci A, Chaloulakou A, Spyrellis N. Exposure to carbon monoxide in the Athens urban area during commuting. Sci Total Environ 2003; 309(1-3): 47-58.

[2] Zuurbier M, Hoek G, Oldenwening M, Meliefste K, van den Hazel. P, Brunekreef B. Respiratory effects of commuters' exposure to air pollution in traffic. Epidemiology 2011; 22(2): 219-27.

[3] Strak M, Boogaard H, Meliefste K, et al. Respiratory health effects of ultrafine and fine particle exposure in cyclists. Occup Environ Med 2010; 67: 118-24.

[4] Kingham S, Dorset W. Assessment of exposure approaches in air pollution and health research in Australia and New Zealand. Clean Air Quality Climate Change (in press).

[5] Adams HS, Nieuwenhuijsen MJ, Colvile RN, McMullen MAS, Khandelwal P. Fine particle (PM2.5) personal exposure levels in transport microenvironments, London, UK. Sci Total Environ 2001; 279(1-3): 29-44.

[6] Kaur S, Nieuwenhuijsen MJ, Colvile RN. Fine particulate matter and carbon monoxide exposure concentrations in urban street transport microenvironments. Atmos Environ 2007; 41(23): 4781810 .

[7] Kaur S, Nieuwenhuijsen MJ. Determinants of personal exposure to PM2.5, ultrafine particle counts, and $\mathrm{CO}$ in a transport microenvironment. Environ Sci Technol 2009; 43(13): 4737-43.

[8] Kingham S, Pattinson W, Shrestha K, Longley I, Salmond JA. Determination of personal exposure to traffic pollution while travelling by different modes. NZ Transport Agency Research Report 457; p. 104. 
[9] Knibbs L, Cole-Hunter T, Morawska L. A review of commuter exposure to ultrafine particles and its health effects. Atmos Environ 2011; 45: 2611-22.

[10] Rank J, Folke J, Jespersen HP. Differences in cyclists and car drivers exposure to air pollution from traffic in the city of Copenhagen. Sci Total Environ 2001; 279(1-3): 131-6.

[11] Boogaard H, Borgman F, Kamminga J, Hoek G. Exposure to ultrafine and fine particles and noise during cycling and driving in 11 Dutch cities. Atmos Environ 2009; 43(27): 4234-42.

[12] Kaur S, Nieuwenhuijsen MJ, Colvile RN. Pedestrian exposure to air pollution along a major road in Central London, UK. Atmos Environ 2005a; 39(38): 7307-20.

[13] Kaur S, Nieuwenhuijsen M, Colvile R. Personal exposure of street canyon intersection users to PM2.5, ultrafine particle counts and carbon monoxide in Central London, UK. Atmos Environ 2005b; 39(20): 3629-41.

[14] Chan LY, Chan CY, Qin Y. The effect of commuting microenvironment on commuter exposures to vehicular emission in Hong Kong. Atmos Environ 1999; 33(11):1777-87.

[15] Flachsbart PG. Human exposure to carbon monoxide from mobile sources. Chemosphere - Global Change Sci 1999; 1(1-3): 301-29.

[16] Liu JJ, Chan CC, Jeng FT. Predicting personal exposure levels to carbon monoxide (CO) in Taipei, based on actual CO measurements in microenvironments and a Monte Carlo simulation method. Atmos Environ 1994; 28(14): 2361-8.

[17] Wong LT, Mui KW, Cheung CT, Chan WY, Lee YH, Cheung CL. In-cabin exposure levels of carbon monoxide, carbon dioxide and airborne particulate matter in air-conditioned buses of Hong Kong. Indoor Built Environ 2011; 20: 464-70.
[18] Vellopoulou AV, Ashmore MR. Personal exposures to carbon monoxide in the city of Athens: I. Commuters' exposures. Environ Int 1998; 24(7): 713-20.

[19] De Bruin YB, Carrer P, Jantunen M, et al. Personal carbon monoxide exposure levels: contribution of local sources to exposures and microenvironment concentrations in Milan. J Exp Anal Environ Epidemiol 2004; 14(4): 312-22.

[20] Saksena S, Quang TN, Nguyen T, Dang PN, Flachsbart P. Commuters' exposure to particulate matter and carbon monoxide in Hanoi, Vietnam. transportation research part D: Transp Environ 2008; 13(3): 206-11.

[21] Panis L, de Geus B, Vandenbulcke G, et al. Exposure to particulate matter in traffic: a comparison of cyclists and car passengers. Atmos Environ 2010; 44(19): 2263-70.

[22] Zuurbier M, Hoek G, van der Hazel P, Brunekreef B. Minute ventilation of cyclists and bus passengers: an experimental study. Environ Health 2009; 8: 48.

[23] Bernmark E, Wiktorin C, Svartengren M, Lewne M, Aberg S. Bicycle messengers: energy expenditure and exposure to air pollution. Ergonomics 2006; 49: 1486-95.

[24] New Zealand Census 2009. quickstat about Auckland region. Retrieved 13 August, 2010, from http://www.stats.govt.nz/

[25] NZTA. State Highway Traffic Data Booklet 2006-2010. New Zealand Transport Agency 2011, Wellington.

[26] Colbeck I, Nasir Z, Ahmad S, Zulfiqar A. Exposure to $\mathrm{PM}_{10}, \mathrm{PM}_{2.5}$, $\mathrm{PM}_{1}$ and carbon monoxide on roads in Lahore, Pakistan. Aerosol Air Quality Res 2011; 11: 689-95.

[27] Chapman L. Transport and climate change: a review. J Transport Geography 2007; 15(5): 354-67.

(C) Dirks et al.; Licensee Bentham Open.

This is an open access article licensed under the terms of the Creative Commons Attribution Non-Commercial License (http: //creativecommons.org/licenses/by$\mathrm{nc} / 3.0 /$ ) which permits unrestricted, non-commercial use, distribution and reproduction in any medium, provided the work is properly cited. 